\title{
Blood pressure control is hard to achieve in patients with chronic renal failure: Results from a survey of renal units in Norway
}

\author{
LINE KATRINE PRØSCH${ }^{1}$, MARIE GRØN SÆLEN ${ }^{1}$, HELGA GUDMUNDSDOTTIR ${ }^{2}$, \\ DAGFINN DYRBEKK ${ }^{3}$, ODD HELGE HUNDERI ${ }^{4}$, ERIK ARNESEN ${ }^{5}$, DAG PAULSEN ${ }^{6}$, \\ HELGE SKJØNSBERG ${ }^{7} \&$ INGRID OS $^{1,2}$
}

${ }^{1}$ Department of Pharmacotherapeutics, University of Oslo, Oslo, Norway, ${ }^{2}$ Ullevål University Hospital, Oslo, Norway, ${ }^{3}$ Vestfold HF, Tønsberg, Norway, ${ }^{4}$ Ostfold HF, Fredrikstad, Norway, ${ }^{5}$ Innlandet HF-Elverum, Elverum, Norway, ${ }^{6}$ Innlandet HF-Lillehammer, Lillehammer, Norway, and ${ }^{7}$ Akershus University Hospital, Nordbyhagen, Norway

\begin{abstract}
Objective. To assess the use of antihypertensive drugs and blood pressure (BP) levels in relation to current guidelines for $\mathrm{BP}$ control in patients with chronic renal failure (CRF). Material and methods. A cross-sectional survey was carried out in six renal outpatient clinics in Oslo and the surrounding area. The hospital records of all renal patients not yet in need of renal replacement therapy and with serum creatinine $\geq 200 \mu \mathrm{mol} / 1$ who attended consultations with nephrologists regularly (at least every third month) were reviewed. Results. Of the 351 patients, $97 \%$ had hypertension. The majority of patients (96\%) were receiving antihypertensive therapy. The average number of antihypertensive drugs being taken was $2.7 \pm 1.3$ (median 3), but it varied with the cause of CRF. The drugs most frequently prescribed as monotherapy were angiotensin-converting enzyme inhibitors or angiotensin II receptor antagonists, which were used by $32 \% ; 51 \%$ of patients were using three or more antihypertensive drugs. Loop diuretics were prescribed as monotherapy in $25 \%$ of cases and in combination with two or more other drugs in $87 \%$. Age and serum creatinine levels influenced the choice of antihypertensive therapy. The target BP of $<130 / 80 \mathrm{mmHg}$ was obtained in $13 \%$ of patients, and lack of optimal BP control was mainly due to systolic hypertension. A total of $38 \%$ of patients had a BP of $<140 / 90 \mathrm{mmHg}$, while $58 \%$ failed to achieve a systolic BP of $<140 \mathrm{mmHg}$. Conclusion. Optimal blood pressure control is hard to achieve in patients with CRF, even with specialist care and the use of multiple antihypertensive drugs.
\end{abstract}

Key Words: Angiotensin-converting enzyme inhibitors, blood pressure control, chronic renal failure, hypertension, loop diuretics

\section{Introduction}

Hypertension is the single most important risk factor for progression of diabetic and non-diabetic kidney disease and renal insufficiency [1-3]. Lowering blood pressure per se leads to organ protection, and medication interfering with the renin-angiotensin system, i.e. angiotensin II receptor antagonists (ARBs) and angiotensin-converting enzyme inhibitors (ACEIs), confers renoprotection beyond that of blood pressure lowering [4-8].

Death from cardiovascular disease in patients with chronic renal failure (CRF) is high and greatly exceeds that of the general population $[9,10]$. It has thus been argued that risk reduction should start during the early stages of renal insufficiency [11]. In high-risk patients, modulation of risk factors, even within what is considered the normal range, may have a great impact on cardiovascular morbidity and mortality $[11,12]$.

Given the benefit of reduction of blood pressure (BP) in this population, there is consensus regarding the importance of good control of BP in patients with chronic kidney disease and renal insufficiency. Thus, recent guidelines based on observational data [13-15] advise lowering BP below 130/ $80 \mathrm{mmHg}$.

Correspondence: Ingrid Os, MD, PhD, Department of Pharmacotherapeutics, University of Oslo, PO Box 1065 , Blindern, 0316 Oslo, Norway. Tel: +47 22840778. Fax: +47 22840771. E-mail: ingrid.os@medisin.uio.no 
Given this background, the aim of this investigation was to assess the use of antihypertensive drugs and BP levels in patients with CRF who had not reached the stage of requiring renal replacement therapy, but were receiving regular care at renal units.

\section{Material and methods}

\section{Study design}

Renal units at six different hospitals in the southern part of Norway participated in a cross-sectional survey based on hospital records of patients with CRF with serum creatinine $\geq 200 \mu \mathrm{mol} / 1$. These hospitals cover the referral area for nephrology for $>1.75$ million Norwegians, close to $40 \%$ of the entire population. The doctors who care for these patients are all highly trained nephrology specialists. During a 6-month period, two of the authors (M. G. S. and L. K. P.) reviewed the hospital records of patients who had been indicated as eligible for the study by consulting nephrologists. Only ambulatory patients could be included, and they had to attend regular consultations at least every third month at the renal unit. Furthermore, they had to have attended a consultation within the previous 3-4 months. Patients with acute renal failure with serum creatinine elevation of $<3$ months duration, or patients who had previously been dialyzed or transplanted could not be included. Current dialysis was also an exclusion criterion. All patients who fulfilled the inclusion criteria were included in the study.

Data from the last visit (within the previous 3 months) were always used. The date of first admission, diagnosis, cardiovascular history (macrovascular disease, i.e. myocardial infarction, stroke, peripheral vascular disease or aortic aneurysm) and laboratory measurements at different times (including the last visit) were recorded. The drug regimen in use at the last visit before the survey was used for registration. The classes of antihypertensive medication were registered, and for loop diuretics the dosage was also registered. For those using bumetanide ( $<5 \%$ of patients), the dose was converted to that for furosemide, i.e. $1 \mathrm{mg}$ of bumetanide $=40 \mathrm{mg}$ of furosemide. BP measurements at the time of admission to hospital and at the last visit before the present investigation were also entered into the database. Pulse pressure (PP) was calculated by subtracting diastolic (D)BP from systolic (S)BP. The most recent measurements of total cholesterol, high-density lipoprotein (HDL) cholesterol, triglycerides and glucose available in the hospital records were noted. Serum creatinine was used as a measure of kidney function. Creatinine clearance could be calculated in two-thirds of the patients using the Cockcroft-Gault formula. Records of proteinuria were often lacking and, if they were present, had been obtained using various methodologies and the results were mostly qualitative or semi-quantitative. Therefore these data were not collected.

The diagnosis of diabetic nephropathy was based on hospital records, as were the other causes of CRF. In the majority of patients the diagnosis is made on the basis of clinical assessments, and only in a minority of cases is it based on renal biopsy. The cause of CRF was categorized as either chronic glomerulonephritis, diabetic nephropathy (types 1 and 2), nephrosclerosis and hypertensive renal disease, chronic pyelonephritis and interstitial nephritis, or other (renal amyloidosis, adult polycystic kidney disease and renal carcinoma, unclassified chronic renal disease).

Patients were labelled as hypertensive based on hospital records of $\mathrm{BP}$ measurements at admission, use of antihypertensive drugs or a BP at the last visit of $>140 / 90 \mathrm{mmHg}$. Controlled and uncontrolled hypertension were defined as a $\mathrm{BP}$ of $<$ and $\geq 130$ / $80 \mathrm{mmHg}$, respectively at the last consultation. The threshold for defining controlled hypertension was also set at $<140 / 90 \mathrm{mmHg}$, and analysed accordingly.

\section{Statistics}

All data are presented as mean \pm SD unless stated otherwise. For differences in BP, 95\% CIs are given as well. For skewed data, the median, Q1 $(25 \%$ percentile) and Q3 (75\% percentile) are given. Comparisons were made using the $\chi^{2}$ test, Student's $t$-test, ANOVA and, for skewed distributions of data, Wilcoxon's test and the Mann-Whitney U-test. Simple bivariate relationships were assessed by calculating Spearman's correlation coefficient. Age and serum creatinine were also categorized in tertiles. The statistical analysis was performed using SPSS statistical software (version 11.0; SPSS Inc., Cary, NC). Two-tailed $p$-values $\leq 0.05$ were considered statistically significant.

\section{Results}

More than 600 hospital records were assessed, and those of 376 Caucasian patients with CRF who were not on dialysis and had never previously been transplanted or dialysed were entered into the database. Of these, 25 did not fulfil the inclusion criterion of serum creatinine $\geq 200 \mu \mathrm{mol} / 1$ at the last visit, and thus data from 351 patients were analyzed.

The mean time from the first referral for chronic kidney disease was 40 months, with a wide range of 
3-394 months. Some of the patient characteristics are given in Tables I and II (patients are categorized according to age tertiles in the latter). Age was positively related, although weakly, to SBP $(r=0.23$, $p<0.001)$ and PP $(r=0.25, p<0.0001)$, while an inverse relationship with DBP was observed $(r=-0.14, p=0.003)$. Serum creatinine did not differ across the age tertiles at the time of investigation, while estimated creatinine clearance $(n=223)$ showed an inverse relationship with age $(r=-0.40$, $p<0.001$ ).

The major cause of CRF in this population of patients attending a renal unit regularly was nephrosclerosis, followed by diabetic nephropathy (Table III). The aetiology of CRF differed with age, with nephrosclerosis being the most prevalent cause in the oldest age group and chronic glomerulonephritis being most frequent in the younger population (Table III). Diabetes nephropathy as a cause of renal failure did not differ significantly across the age tertiles. The presence of macrovascular disease increased across the age tertiles (Table II).

\section{Use of drugs}

Multipharmacy was frequent, with a median of three drugs $(2.7 \pm 1.3)$ being prescribed, while only $3.9 \%$

Table I. Charateristics of the study population $(n=351)$. Unless stated otherwise, data are presented as mean (SD).

\begin{tabular}{|c|c|}
\hline Characteristics & Value \\
\hline Age (years) & $63.0(15.9)$ \\
\hline Females $(\%)$ & 27.9 \\
\hline Hypertension (\%) & 96.6 \\
\hline Macrovascular disease (\%) & 37.6 \\
\hline Coronary heart disease $(\%)$ & 29.6 \\
\hline $\mathrm{SBP}^{2^{\mathrm{a}}}(\mathrm{mmHg})$ & $155.7(25.6)$ \\
\hline $\mathrm{SBP}^{2^{\mathrm{b}}}(\mathrm{mmHg})$ & $142.6(21.0)$ \\
\hline $\mathrm{DBP}^{2^{\mathrm{a}}}(\mathrm{mmHg})$ & $87.6(16.1)$ \\
\hline $\mathrm{DBP}^{2^{\mathrm{b}}}(\mathrm{mmHg})$ & $80.4(10.9)$ \\
\hline $\mathrm{PP}^{2^{\mathrm{a}}}(\mathrm{mmHg})$ & $68.1(19.8)$ \\
\hline $\mathrm{PP}^{2^{\mathrm{b}}}(\mathrm{mmHg})$ & $62.0(15.9)$ \\
\hline Serum creatinine ${ }^{2^{\mathrm{a}}}(\mu \mathrm{mol} / \mathrm{l})$ & $269(162)$ \\
\hline Serum creatinine ${ }^{2^{\mathrm{b}}}(\mu \mathrm{mol} / \mathrm{l})$ & $338(133)$ \\
\hline Creatinine clearance ${ }^{2^{b}}(\mathrm{ml} / \mathrm{min})^{\star}$ & $24.7(11.8)$ \\
\hline Serum carbamide $2^{2^{\mathrm{b}}}(\mathrm{mmol} / \mathrm{l})$ & $20.4(6.7)$ \\
\hline Haemoglobin $^{2^{\mathrm{b}}}(\mathrm{g} / \mathrm{dl})$ & $12.2(1.6)$ \\
\hline Base excess $(\mathrm{mmol} / \mathrm{l})$ & $-2.7(3.7)$ \\
\hline Phosphate $(\mathrm{mmol} / \mathrm{l})$ & $1.5(0.4)$ \\
\hline Alkaline phosphatase (U/l) & $169(105)$ \\
\hline Total cholesterol (mmol/l) & $5.2(1.2)$ \\
\hline HDL cholesterol (mmol/l) & $1.2(0.4)$ \\
\hline Triglycerides $(\mathrm{mmol} / \mathrm{l})$ & $2.2(1.4)$ \\
\hline Glucose $(\mathrm{mmol} / \mathrm{l})$ & $6.3(2.6)$ \\
\hline
\end{tabular}

${ }^{\mathrm{a}}$ At referral.

${ }^{\mathrm{b}}$ At the time of the present investigation.

${ }^{\mathrm{c} C a l c u l a t e d}$ using the Cockcroft-Gault formula, corrected for gender. of patients were not prescribed any antihypertensive therapy. Overall, the most frequently used drugs were loop diuretics, which were used by $65.8 \%$ of patients, with an average dose of $125 \pm 124 \mathrm{mg}$ (median $80 \mathrm{mg} ;$ Q1-Q3 40-160 mg). Calcium channel blockers (CCBs) were used by $60.2 \%$ of patients, beta-adrenergic receptor blockers (BBs) by $52.8 \%$ and ACEIs or ARBs by $45.1 \%$. Other drugs, i.e. alpha-receptor blockers, alphamethyldopa, thiazides or moxonidine, were used by $39.0 \%$. ACEIs or ARBs were most frequently used as monotherapy, while loop diuretics were used as monotherapy by $25 \%$ of patients (Table IV). None of the patients in the current survey used a combination of ACEIs and ARBs.

The use of medication seemed to differ across the range of serum creatinine levels, with a significant decrease in the use of ACEIs and ARBs with rising creatinine levels, while the use of CCBs and diuretics remained the same (Figure 1). Loop diuretics were the most frequently used drugs in the oldest age groups $(p=0.07)$. The dosage of loop diuretics also seemed to be higher in the oldest patients, but this did not reach statistical significance $(p=0.27)$. There was a marked decrease in the use of ACEIs or ARBs with increasing age $(p<0.0001)$, with less than a quarter of the oldest patients using these classes of drugs. BBs were also more frequently used in the oldest patients $(p=0.006)$. Overall use of statins was $48.3 \%$, and did not differ between age groups $(p=0.77)$. The cause of CRF influenced the use of antihypertensive drugs (Figure 2), and this was not explained by differences in SBP $(p=0.16)$, $\operatorname{DBP}(p=0.35)$ or serum creatinine $(p=0.58)$.

\section{$B P$ levels}

Overall, there was a highly significant decrease in BP in the hypertensive patients after referral to hospital (Figure 3). The decrease in SBP was $13.9 \pm 27.2$, $95 \%$ CI $10.9-16.9 \mathrm{mmHg}(p<0.001)$, in DBP $7.7 \pm 16.4,5.6-9.5 \mathrm{mmHg}(p<0.001)$ and in $\mathrm{PP}$ $6.2 \pm 19.8,4.0-8.4 \mathrm{mmHg}(p<0.001)$.

Only $13 \%$ of patients had BP levels $<130 / 80$ $\mathrm{mmHg}$, and fewer patients obtained a decrease in SBP compared to DBP ( $18 \%$ vs $34 \%)$. The proportion of patients achieving a BP of $<140 /$ $90 \mathrm{mmHg}$ was $38 \%$, but systolic hypertension (SBP $\geq 140 \mathrm{mmHg}$ ) was still prevalent $(58 \%)$, while a DBP of $\leq 90 \mathrm{mmHg}$ was observed in $75 \%$ of cases. Systolic hypertension was more frequent in older patients $(p=0.003)$.

The PP was significantly lower in patients with a $\mathrm{BP}$ of $<130 / 80 \mathrm{mmHg}$ than in those with uncontrolled BP $(43.5 \pm 8.4$ vs $66.9 \pm 17.0 \mathrm{mmHg} ; p=$ 0.0001). Furthermore, PP differed depending on 
Table II. Characteristics of the study population $(n=351)$ classified in age tertiles. Unless stated otherwise, data are presented as mean (SD).

\begin{tabular}{lcccc}
\hline & \multicolumn{3}{c}{ Age tertile } \\
\cline { 2 - 5 } Characteristic & \multicolumn{1}{c}{ 1st } & 2nd & 3rd & \multicolumn{2}{c}{$p$} \\
\hline Age (years) & $45.7(10.6)$ & $50.6(3.8)$ & $78.1(4.0)$ & $<0.001$ \\
Females (\%) & 31 & 27 & 23 & 0.39 \\
Hypertension (\%) & 91.2 & 96.2 & 96.7 & 0.16 \\
Macrovascular disease (\%) & 13.3 & 44.8 & 59.5 & $<0.001$ \\
Time from first referral (months) & $45(50)$ & $50(67)$ & $27(33)$ & 0.003 \\
$\mathrm{SBP}^{2^{\mathrm{b}}}(\mathrm{mmHg})$ & $138.9(20.2)$ & $144.9(18.3)$ & $146.6(23.3)$ & 0.015 \\
$\mathrm{DBP}^{2^{\mathrm{b}}}(\mathrm{mmHg})$ & $83.3(11.5)$ & $80.9(9.5)$ & $78.1(1.0)$ & 0.001 \\
$\mathrm{PP}^{2^{\mathrm{b}}}(\mathrm{mmHg})$ & $55.5(17.1)$ & $63.9(16.5)$ & $68.5(19.0)$ & $<0.001$ \\
Serum creatinine $^{2^{\mathrm{a}}}(\mu \mathrm{mol} / \mathrm{l})$ & $236(153)$ & $287(207)$ & $283(116)$ & 0.03 \\
Serum creatinine $^{2^{\mathrm{b}}}(\mu \mathrm{mol} / \mathrm{l})$ & $331(124)$ & $339(128)$ & $341(131)$ & 0.828 \\
Serum carbamide $^{\mathrm{b}^{\mathrm{b}}}(\mathrm{mmol} / \mathrm{l})$ & $19.8(5.7)$ & $19.9(6.4)$ & $20.4(7.7)$ & 0.073 \\
Haemoglobin $^{\mathrm{b}}(\mathrm{g} / \mathrm{dl})$ & $12.3(1.8)$ & $12.2(1.4)$ & $12.0(1.6)$ & 0.18 \\
\hline
\end{tabular}

${ }^{\mathrm{a}}$ At referral.

${ }^{\mathrm{b}}$ At the time of the present investigation.

whether SBP but not DBP was controlled. PP was significantly lower in patients with an SBP of $<130 \mathrm{mmHg}$ than in those with an SBP of $\geq 130 \mathrm{mmHg}(48.5 \pm 10.8$ vs $64.8 \pm 18.2 \mathrm{mmHg}$; $p<0.001)$. There was no difference in PP in those with a DBP of $<80 \mathrm{mmHg}(64.3 \pm 18.7$ vs $61.6 \pm$ $18.1 \mathrm{mmHg} ; p=0.19$ ).

The median change in serum creatinine levels for all patients from the time of referral to the time-point of the survey was $+55 \mu \mathrm{mol} / 1(-4$ to $+147 \mu \mathrm{mol} / \mathrm{l})$. There was a weak correlation between the change in serum creatinine level and DBP at the referral time $(r=0.22, p<0.001)$, but there was no corresponding correlation with SBP $(r=0.14, p=\mathrm{NS})$.

Those patients who experienced a rise in serum creatinine level between the time of referral and the time of the survey had a higher DBP at the time of referral compared to those with a decrease in creatinine level $(89.4 \pm 15.2$ vs $81.2 \pm 17.2 \mathrm{mmHg}$; mean difference $8.2 \pm 4.1 \mathrm{mmHg} ; p<0.001$ ), but there was no significant difference in SBP $(156.8 \pm$ 24.7 vs $151.8 \pm 28.3 \mathrm{mmHg} ; p=\mathrm{NS}$ ). No difference in PP was observed either $(67.4 \pm 19.2$ vs $70.6 \pm$ $21.0 \mathrm{mmHg} ; p=\mathrm{NS}$ ).

\section{Discussion}

Close to $97 \%$ of our patients with CRF had elevated $\mathrm{BP}$ or were being treated with antihypertensive drugs, comparable with the prevalence of hypertension observed in a large American study [16].

This was a highly selected group of patients as they were receiving regular care from nephrologists but, despite an impressive decrease in BP between the referral time and the present survey, BP control was not optimal. Only $13 \%$ of patients had BP levels in accordance with current recommendations $(<130 / 80 \mathrm{mmHg})$, and uncontrolled SBP was the major cause of failure to meet that target. The proportion of patients who achieved the more conservative BP goal of $<140 / 90 \mathrm{~mm} \mathrm{Hg}$ was $38 \%$, in accordance with other reports [16-18]. This figure is an improvement on what has been achieved among patients with essential hypertension in general practice [19].

PP has emerged as an important and independent risk factor for cardiovascular disease [20] and has recently been put forward as a major determinant of progression of renal disease and renal insufficiency [2]. Some authors have therefore suggested that

Table III. Diagnoses of patients with CRF in different age tertiles. Values are presented as percentages.

\begin{tabular}{lrrrr}
\hline & \multicolumn{3}{c}{ Age tertile } \\
\cline { 2 - 5 } Diagnosis & 1st & 2nd & 3rd & All \\
\hline Nephrosclerosis & 22.9 & 37.0 & 51.6 & 37.4 \\
Diabetic nephropathy & 17.8 & 26.9 & 19.8 & 21.3 \\
Chronic glomerulonephritis & 27.1 & 15.7 & 12.9 & 18.7 \\
Chronic pyelonephritis/interstitial nephritis & 16.9 & 11.1 & 8.0 & 12.0 \\
Others & 15.2 & 9.2 & 6.8 & 10.5 \\
\hline
\end{tabular}


Table IV. Usage (\%) of different classes of antihypertensive drugs given as monotherapy, with one other drug or with two or more other drugs.

\begin{tabular}{lccc}
\hline & \multicolumn{3}{c}{ Form of administration } \\
\cline { 2 - 4 } & $\begin{array}{c}\text { As } \\
\text { Antihypertensive }\end{array}$ & $\begin{array}{c}\text { With one } \\
\text { mother drug }\end{array}$ & $\begin{array}{c}\text { With two or more } \\
\text { other drugs }\end{array}$ \\
\hline ACEIs/ARBs & 32 & 42 & 51 \\
CCBs & 18 & 48 & 83 \\
BBs & 13 & 40 & 75 \\
Loop diuretics & 25 & 55 & 87 \\
Others & 2 & 18 & 65 \\
\hline
\end{tabular}

rather than aiming at good control of DBP, the focus should be on controlling SBP and PP [2]. In elderly hypertensive subjects with isolated systolic hypertension, an increase in $\mathrm{PP}$ of $10 \mathrm{mmHg}$ confers increased risks of congestive heart failure and stroke of $32 \%$ and $24 \%$, respectively [21].

The number of patients in the present study is too small to enable definite conclusions to be drawn regarding differences in the prevalence of hypertension depending on the aetiology of CRF, as others have done $[16,17]$. However, we did note a difference in the use of antihypertensive drugs depending on aetiology, as the number of drugs prescribed was higher in patients with diabetic nephropathy or nephrosclerosis compared to those with chronic glomerulonephritis.

Some of the usual barriers to good BP control, e.g. access to good healthcare, cannot explain our finding of a low rate of optimal BP control as specialist hospital care was a prerequisite for entering the study. The majority of our patients required multiple antihypertensive drugs: the average number of drugs prescribed in the present study was higher than that

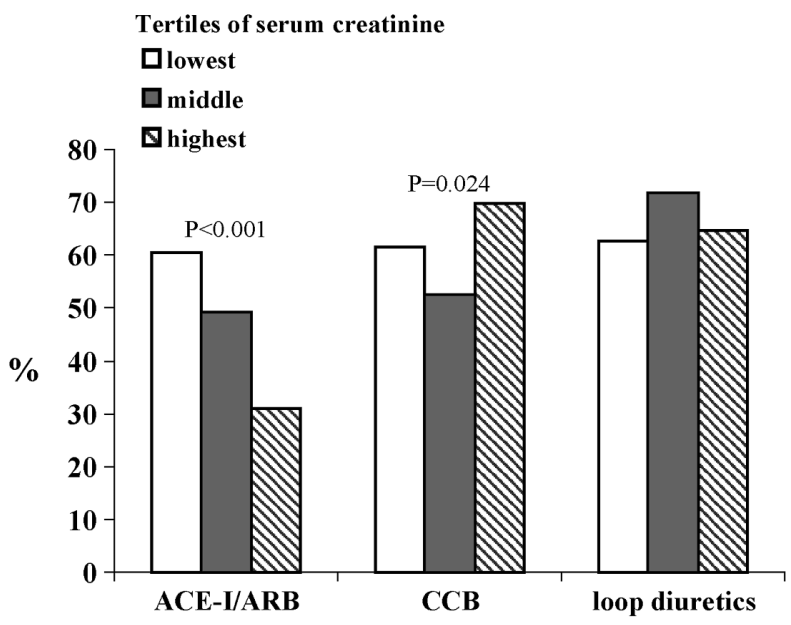

Figure 1. Use of different antihypertensive drugs in the different serum creatinine tertiles in patients with CRF with serum creatinine levels $\geq 200 \mathrm{~mol} / \mathrm{l}$. Comparisons were made using one-way ANOVA.

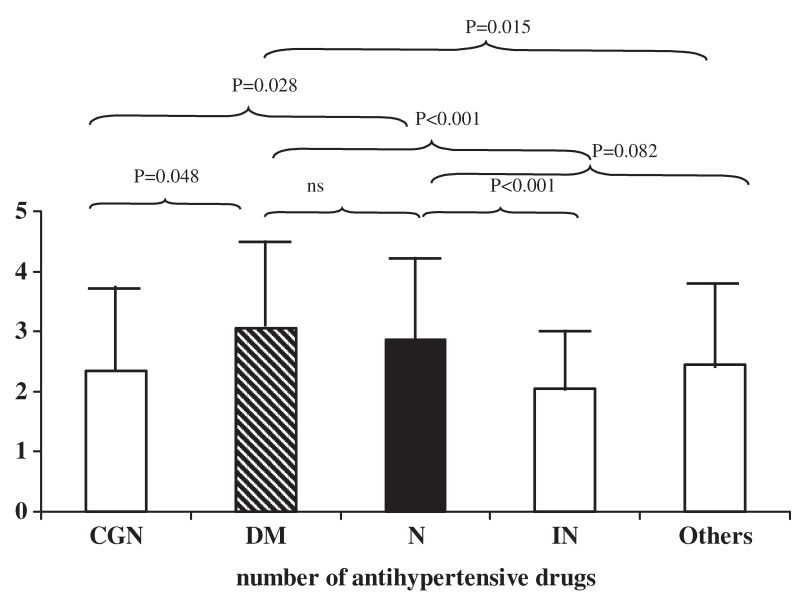

Figure 2. The number of antihypertensive drugs used according to the aetiology of CRF. CGN =chronic glomerulonephritis; $\mathrm{DM}=$ diabetes mellitus; $\mathrm{N}=$ nephrosclerosis/hypertensive renal disease; $\mathrm{IN}=$ interstitial nephritis/chronic pyelonephritis. Comparisons between different groups were made using Wilcoxon's test.

reported in other studies [17], but similar to that used in randomized clinical trials [4,6,22]. The patients in the present survey had more severe renal impairment than those in comparable studies addressing BP control, and our patients also suffered more from macrovascular disease.

Multipharmacy was prevalent, and the majority of patients used two or more drugs. Drugs interfering with the renin-angiotensin system were those most frequently used as monotherapy, but they were also prescribed to more than half of patients using three or more antihypertensive drugs. Overall, loop diuretics were the most frequently prescribed antihypertensive drugs. While a quarter of patients receiving monotherapy used loop diuretics, the proportion rose to $87 \%$ when three or more drugs were prescribed. Furthermore, a high proportion of patients used CCBs and BBs. Among younger patients, ACEIs or ARBs were more often preferred, which were used in only a minority in the upper age group.

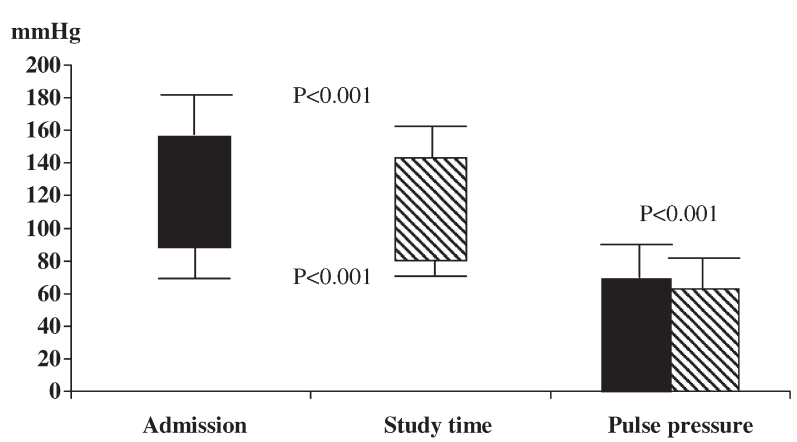

Figure 3. BP levels and PP at the time of admission to a renal unit (solid bars) and at the time of the study (hatched bars) in patients with CRF and hypertension $(n=339)$. 
The use of diuretics increased in the oldest age group.

The frequent choice of ACEIs or ARBs is not surprising given the results of recent clinical trials in both diabetic and non-diabetic kidney disease indicating a renoprotective role of these drugs beyond that which can be explained by blood pressure lowering $[2,4-8,22]$. Excess volume plays an important role in developing and sustaining hypertension in CRF [23] and therefore use of loop diuretics is frequent, as observed in our study. As the effect of loop diuretics is dependent on renal function, the dose should be increased in this patient population, which may lead to improved BP control. Combination therapy with ACEIs and ARBs has been proposed [24-26], but none of the patients used this combination in the present survey. As kidney function declines, the risk of accumulation of ACEIs increases, and this is probably the major cause for the decreased usage of ACEIs with advancing renal failure. However, this could lead to use of these drug classes being overly restricted in patients who may benefit from the treatment $[27,28]$.

CCBs are recommended in the form of combination therapy in renal patients [29]. It has been proposed [30,31] that CCBs may be particularly beneficial in patients with end-stage renal failure with disturbances of calcium-phosphate metabolism. However, a more likely explanation for the frequent use of CCBs is their safety profile in this setting.

Newer data [32,33] suggest that sympathetic overactivity is an important contributor to hypertension in renal failure, and renal patients may therefore benefit from the use of BBs. Furthermore, a substantial number of patients in the current survey were suffering from coronary heart disease, which would have increased the use of BBs.

Based on the strict inclusion criteria we used to select our patients, our findings may not be applicable to patients with creatinine values $<200 \mu \mathrm{mol} / \mathrm{l}$, those attending outpatient examinations at regular intervals of $>3$ months or not on a regular basis and patients attending examinations but with consultants other than a nephrologist.

A further limitation of this study is that it was based on data from hospital charts. We have no information about compliance with or adherence to the prescribed drug regimens. The BP recordings were all taken in a sitting position and in accordance with good clinical practice, and these measurements were the ones the nephrologists based their decisions on. In the majority of cases, the cause of CRF is determined based on clinical assessment rather than renal biopsy. This may lead to overestimation of the incidences of nephrosclerosis and diabetic nephro- pathy. However, the high number of cases of nephrosclerosis or hypertensive renal disease that were registered in the present survey is in accordance with the increase in prevalence observed in other European countries, and also in agreement with reports from the Norwegian registry for patients enrolled in dialysis treatment or transplantation programmes [34]. Hypertension as a primary cause of end-stage renal failure has risen from $5 \%$ to $28 \%$ over the last 20 years, while chronic glomerulonephritis has decreased from $34 \%$ to $17 \%$ [34].

This study took place in 2003, the same year in which new guidelines were issued [13-15]. There seems to be a consensus regarding the target BP in patients with nephropathy, despite the fact that the guidelines are based on observational findings and there is a paucity of findings from clinical trials. However, in some studies [35] the renoprotective effect of a target $\mathrm{BP}$ of $<130 / 80 \mathrm{mmHg}$, as opposed to $<140 / 90 \mathrm{mmHg}$, is not supported.

In conclusion, although hypertension is the single most important risk factor for progression of chronic kidney disease, and a major risk factor for cardiovascular disease in renal patients, BP control in this high-risk population is far from optimal, despite the extensive use of multiple antihypertensive drugs. Randomized controlled studies defining the threshold for optimal BP control in patients with CRF are clearly needed. Based on our observations, we suggest that a higher dosage of loop diuretics should be considered to improve $\mathrm{BP}$ control in renal patients, and that the use of drugs interfering with the renin-angiotensin system should be carefully scrutinized in these patients.

\section{Acknowledgements}

We are grateful for the practical help of the staff at the renal outpatient clinics and medical archives of the participating hospitals. This study was supported by grants from the Norwegian Renal Association.

\section{References}

[1] Peterson JC, Adler S, Burkart JM, Greene T, Hebert LA, Hunsicker LG, et al. Blood pressure control, proteinuria, and the progression of renal disease. The Modification of Diet in Renal Disease Study. Ann Intern Med 1995; 123:754-62.

[2] Bakris GL, Weir MR, Shanifar S, Zhang Z, Douglas J, van Dijk DJ, et al. Effects of blood pressure level on progression of diabetic nephropathy: results from the RENAAL study. Arch Intern Med 2003;163:1555-65.

[3] Vikse BE, Aasarod K, Bostad L, Iversen BM. Clinical prognostic factors in biopsy-proven benign nephrosclerosis. Nephrol Dial Transplant 2003;18:517-23.

[4] Lewis EJ, Hunsicker LG, Clarke WR, Berl T, Pohl MA, Lewis JB, et al. Renoprotective effect of the angiotensin- 
receptor antagonist irbesartan in patients with nephropathy due to type 2 diabetes. N Engl J Med 2001;345:851-60.

[5] Lewis EJ, Hunsicker LG, Bain RP, Rohde RD. The effect of angiotensin-converting-enzyme inhibition on diabetic nephropathy. The Collaborative Study Group. N Engl J Med 1993;329:1456-62.

[6] Wright JT Jr, Bakris G, Greene T, Agodoa LY, Appel LJ, Charleston J, et al. Effect of blood pressure lowering and antihypertensive drug class on progression of hypertensive kidney disease: results from the AASK trial. JAMA 2002;288:2421-31.

[7] Agodoa LY, Appel L, Bakris GL, Beck G, Bourgoignie J, Briggs JP, et al. Effect of ramipril vs amlodipine on renal outcomes in hypertensive nephrosclerosis: a randomized controlled trial. JAMA 2001;285:2719-28.

[8] Maschio G, Alberti D, Janin G, Locatelli F, Mann JF, Motolese $\mathrm{M}$, et al. Effect of the angiotensin-convertingenzyme inhibitor benazepril on the progression of chronic renal insufficiency. The Angiotensin-Converting-Enzyme Inhibition in Progressive Renal Insufficiency Study Group. N Engl J Med 1996;334:939-45.

[9] Baigent C, Burbury K, Wheeler D. Premature cardiovascular disease in chronic renal failure. Lancet 2000;356:147-52.

[10] Ruilope LM, van Veldhuisen DJ, Ritz E, Luscher TF. Renal function: the Cinderella of cardiovascular risk profile. J Am Coll Cardiol 2001;38:1782-7.

[11] Rabelink TJ. Cardiovascular risk in patients with renal disease: treating the risk or treating the risk factor? Nephrol Dial Transplant 2004;19:23-6.

[12] Law MR, Wald NJ. 2002. Risk factor thresholds: their existence under scrutiny. Br Med J; 324:1570-6

[13] K/DOQI clinical practice guidelines for chronic kidney disease: evaluation, classification, and stratification. Am J Kidney Dis 2002;39(2 Suppl 1):S1-266.

[14] 2003 European Society of Hypertension-European Society of Cardiology guidelines for the management of arterial hypertension. J Hypertens 2003;21:1011-53.

[15] 2003 World Health Organization (WHO)/International Society of Hypertension (ISH) statement on management of hypertension. J Hypertens 2003;21:1983-92.

[16] Buckalew VM Jr, Berg RL, Wang SR, Porush JG, Rauch S, Schulman G. Prevalence of hypertension in 1,795 subjects with chronic renal disease: the modification of diet in renal disease study baseline cohort. Modification of Diet in Renal Disease Study Group. Am J Kidney Dis 1996;28:811-21.

[17] Ridao N, Luno J, Garcia de Vinuesa S, Gomez F, Tejedor A, Valderrabano F. Prevalence of hypertension in renal disease. Nephrol Dial Transplant 2001;16(Suppl 1):70-3.

[18] Coresh J, Wei GL, McQuillan G, Brancati FL, Levey AS, Jones C, et al. Prevalence of high blood pressure and elevated serum creatinine level in the United States: findings from the third National Health and Nutrition Examination Survey (1988-1994). Arch Intern Med ;161 1988;2001:1207-16.

[19] Westheim A, Klemetsrud T, Tretli S, Stokke HP, Olsen H. Blood pressure levels in treated hypertensive patients in general practice in Norway. Blood Press 2001;10:37-42.

[20] Blacher J, Staessen JA, Girerd X, Gasowski J, Thijs L, Liu L, et al. Pulse pressure not mean pressure determines cardio- vascular risk in older hypertensive patients. Arch Intern Med 2000;160:1085-9.

[21] Vaccarino V, Berger AK, Abramson J, Black HR, Setaro JF, Davey JA, et al. Pulse pressure and risk of cardiovascular events in the systolic hypertension in the elderly program. Am J Cardiol 2001;88:980-6.

[22] Brenner BM, Cooper ME, de Zeeuw D, Keane WF, Mitch WE, Parving $\mathrm{HH}$, et al. Effects of losartan on renal and cardiovascular outcomes in patients with type 2 diabetes and nephropathy. N Engl J Med 2001;345:861-9.

[23] Vasavada N, Agarwal R. Role of excess volume in the pathophysiology of hypertension in chronic kidney disease. Kidney Int 2003;64:1772-9.

[24] Nakao N, Yoshimura A, Morita H, Takada M, Kayano T, Ideura $\mathrm{T}$. Combination treatment of angiotensin-II receptor blocker and angiotensin-converting-enzyme inhibitor in nondiabetic renal disease (COOPERATE): a randomised controlled trial. Lancet 2003;361:117-24.

[25] Laverman GD, Navis G, Henning RH, de Jong PE, de Zeeuw D. Dual renin-angiotensin system blockade at optimal doses for proteinuria. Kidney Int 2002;62:1020-5.

[26] Tylicki L, Rutkowski P, Renke M, Rutkowski B. Renoprotective effect of small doses of losartan and enalapril in patients with primary glomerulonephritis. Short-term observation. Am J Nephrol 2002;22:356-62.

[27] Pisoni R, Faraone R, Ruggenent P, Remuzzi G. Inhibitors of the renin-angiotensin system reduce the rate of GFR decline and end-stage renal disease in patients with severe renal insufficiency. J Nephrol 2002;15:428-30.

[28] Ruggenenti P, Perna A, Remuzzi G. ACE inhibitors to prevent end-stage renal disease: when to start and why possibly never to stop: a post hoc analysis of the REIN trial results. Ramipril Efficacy in Nephropathy. J Am Soc Nephrol 2001;12:2832-7.

[29] Locatelli F, Del Vecchio L, Andrulli S, Colzani S. Role of combination therapy with ACE inhibitors and calcium channel blockers in renal protection. Kidney Int Suppl 2002;82:53-60.

[30] Tepel M, Giet MV, Park A, Zidek W. Association of calcium channel blockers and mortality in haemodialysis patients. Clin Sci (Lond) 2002;103:511-5.

[31] Kestenbaum B, Gillen DL, Sherrard DJ, Seliger S, Ball A, Stehman-Breen C. Calcium channel blocker use and mortality among patients with end-stage renal disease. Kidney Int 2002;61:2157-64.

[32] Orth SR, Amann K, Strojek K, Ritz E. Sympathetic overactivity and arterial hypertension in renal failure. Nephrol Dial Transplant 2001;16(Suppl 1):67-9.

[33] Laverman GD, Remuzzi G. Antihypertensive therapy in chronic renal disease: a place for sympathicolytic agents? J Hypertens 2003;21:1625-6.

[34] Available from: www.nephro.no/registry/aarsm2002.html

[35] Schrier RW, Estacio RO, Esler A, Mehler P. Effects of aggressive blood pressure control in normotensive type 2 diabetic patients on albuminuria, retinopathy and strokes. Kidney Int 2002;61:1086-97. 